\title{
Understanding the Relationship Between Health PACs and Health Lobbying in the American States
}

\author{
David Lowery \\ Department of Political Science \\ University of Leiden \\ Leiden 2300RB \\ The Netherlands \\ Virginia Gray \\ Jennifer Benz \\ Mary Deason \\ Justin Kirkland \\ Jennifer Sykes \\ Department of Political Science \\ University of North Carolina at Chapel Hill \\ Chapel Hill, North Carolina 27599-3265 \\ USA
}

This paper was prepared for presentation at the Annual Meeting of the Midwest Political Science Association, Chicago, Illinois, April, 2008. This research was supported by a Robert Wood Johnson Foundation Investigator Award in Health Policy Research (ID\#047727). We thank Rachel Weiss at the National Institute on Money in State Politics for her assistance in procuring the data for us and helping us understand it. 


\begin{abstract}
We examine whether and how health PAC activity in the states is connected to lobbying. Is the political money that health interest organizations bring to the policy process a powerful, independent means of influence or is it better understood more narrowly as a lobbing tactic used to support lobbying? We examine a range of conjectures on the relationship between campaign contributions and lobby activity and the limited work that has been conducted on them and raise a number of questions about the process by which they are connected. We test these hypotheses with 1998 data on state lobbying and PAC activity. We conclude that PAC activity is best viewed as an adjunct of lobbying rather than an independent form of political activity.
\end{abstract}




\section{Understanding the Relationship Between Health PACs and Health Lobbying in the American States}

While the national government has accomplished little - with the partial exception of expansion of Medicare to cover prescription drugs - in regard to health policy reform over the last two decades, the states have done a great deal. Indeed, during the 1990s, the states successfully addressed many of the health care issues seemingly stalemated on the national level. Between 1995-2001, for example, the 50 states passed over 900 different laws regulating managed care. By 2004, 31 states had passed some kind of pharmaceutical assistance law, using state funds to pay for a portion of the cost of drugs for eligible senior residents. ${ }^{1}$ But despite a number of incremental policy events - ranging from studies, bill introductions, the passage of bills by legislatures, and even the signing of these bills into law - the states collectively have been no more successful than the federal government in achieving universal insurance coverage. Further, even the successes have varied markedly across the states, with some doing very little.

This variation in patterns of success among the states is interesting in that it allow us to test hypotheses about casual relationships among policies and their determinants that are simply not possible at the national level. Among the most important of these is the claim that organized interests in general and the political money that they bring to the policy process in particular have stymied efforts to adopt the kinds of health care policies routinely found in civilized countries such as The Netherlands. At the national level, of course, organized interests are widely credited with the blocking of broad-based reform of the health care system. A number of scholars (e.g., West, Heith, and Goodwin, 1996; Weissert and Weissert, 2002; Jamieson, 1994a-c; West and Loomis, 1998; Quadagno, 2005) and journalists (Johnson and Broder, 1996) blamed President Bill Clinton's health care fiasco on powerful interest organizations representing the health care industry. There is no question that considerable money is spent on lobbying by health care interests at the national level. But with a single observation of money and a single policy

\footnotetext{
${ }^{1}$ National Conference of State Legislators (NCSL), www.ncsl.org.
} 
outcome, the national government provides little analytic leverage with which to unpack this claim. In contrast, taking advantage of variations in cause and effects, studies have found that the density and mix of health interests found in the states has influenced the adoption of managed care regulations (Gray, Lowery, and Godwin 2007a), steps toward comprehensive health care (Gray, Lowery, Godwin, and Monogan 2005), and the implementation (but not the adoption) of drug assistance programs (Gray, Lowery, and Godwin 2007b). Still, these analyses suggest that the relationship between lobbying and policies is more complex and varied than suggested by those who argue that powerful interests always and everywhere arrange things to their liking.

We extend this work here by examining the role of campaign contributions by health interests in the context of the larger lobbying system in the states. More specifically, we examine whether and how health PAC activity in the states - as measured by the density of health PACs and their level of campaign contributions - is connected to lobbying activity. ${ }^{2}$ Is the political money that health interests bring to the politics a powerful, independent means of influence, or is it better understood more narrowly as a tactic used to support lobbying? To answer this question, we first examine a range of conjectures about the relationship between campaign contributions and lobbying and the limited work that has been done on them. Further, we extend these analyses by raising a number of as yet unanswered questions about the process by which lobbying is linked to campaign finance. We then test these hypotheses with 1998 data on state lobbying and PAC activity. Finally, we conclude with observations about the role of PACs in the lobbying system, reconsidering the likelihood that campaign finance activity on the part of organized interests can independently influence the adoption of health policy reforms in the states.

\section{Questions about PACs and Lobbying}

The existing literature provides a rather mixed picture of the relationship between the lobbying activities of organized interests and the campaign finance activities of PACs. Research

\footnotetext{
${ }^{2}$ Given variations in state laws, we use the term PAC here to more broadly represent "non-individual, nonparty" contributors to state political campaigns. We discuss this issue further when we present our data.
} 
relying on surveys of interest groups operating in D.C. has found only a relatively weak link between lobbying and campaign contribution activity (Berry 1977; Wright 1985; Schlozman and Tierney 1986; Gais and Walker 1991). Simply put, many organizations that lobby do not make campaign contributions and many, even most, PACs do not lobby. This result has been replicated at the state level as well. An analysis of surveys of interest organizations in three states by Nownes and Freeman (1998) reported that less than half of the interest organizations made campaign contributions. Thus, PACs appeared to an independent means to influence policy via the election process, one that had little direct relationship with lobbying sitting legislators.

At the same time, however, many scholars treated the census of national PACs as essentially synonymous with a census of organizations engaged in lobbying, using the same theoretical tools employed to understand the formation and density of the PAC population as used to study the mobilization of interest organizations (Andres 1985; Masters and Keim 1985; Boies 1989; Humphries 1991; McKeown 1994; Grier, Munger, and Roberts 1991; 1994; Conybeare and Squire 1994). ${ }^{3}$ This was perhaps understandable in the 1980s and early 1990 s given the lack of available data on national lobbying activity. The Federal Election Campaign Act mandated the collection of PAC data only after 1971 while information on lobbying was collected only after the passage the Lobby Disclosure Act in 1995. Still, this research entailed a very strong - and uniformly untested - assumption that the number of distribution of organizations engaged in campaign finance activities reflected the number and distribution of organizations engaged in lobbying. At a minimum, the very weak relationship reported in the surveys of organized interests noted above should have raised concerns about this assumption.

Still, the larger literature on PACs has always asserted that there was a strong connection between the campaign activities of PACs and the lobbying activities of organized interests. Hall and Wayman $(1990,799)$, for example, argue that the expected returns from investing via PACs

\footnotetext{
${ }^{3}$ Especially important in this regard is the routine use of Mancur Olson's (1965) theory of collective action in this literature to explain the density of PAC populations, an approach that is now viewed as inappropriate for a number of reasons (Lowery, Gray, and Monogan 2008).
} 
in an electoral strategy of replacing incumbents are prohibitively low and have a great risk should incumbents win re-election. Instead, most PAC scholars have argued contributions are employed as part of a lobbying process focused on influencing the decisions of incumbent legislators. As Humphries (1991, 363), "it is not PACs per se that corporations value, but the ability of PAC money to facilitate the job of Washington representatives." In support of this claim, Matasar $(1986,52)$ and Sorauf $(1984,73)$ noted that strong ties between the governance structures of PACs and their affiliated lobbying organizations. Stronger still, analyses of PAC allocation patterns, which found that incumbents are the primary beneficiaries of campaign contributions, found little evidence of widespread reliance on an independent, PAC-based electoral strategy of influence on the part of interest organizations (Wright 1989; 1990; Hall and Wayman 1990; Herndon 1982; Grenzke 1989). But why should interest organizations rely on PACs at all when lobbying is the goal? As one corporate executive noted to Sabato (1984, 122), "Talking to politicians is a fine thing but with a little money they hear you better."

We have, then, three quite divergent and even inconsistent bodies of work on the relationship between lobbying and the campaign contributions of PACs. Two studies, however, are especially useful in helping us to reconcile these conflicting interpretations. The first is Tripathi, Ansolabehere, and Snyder (2002) analysis of the overlap between organized interests registered to lobby, based on some of the earliest 1997 and 1998 lobbying reports compiled from the Lobby Disclosure Act of 1995, and PAC contributions from 1988 to 1998 as reported by the Federal Election Commission. Their findings provided superficial support for the survey-based claim that there is little connect between the PAC and lobbying populations of organized interests. That is, Tripathi and his colleagues found that fully 74.50 percent of the lobbying organizations had no PAC, while 52.84 percent of PACs were unaffiliated with an organization registered to lobby. Indeed, in a finding that sharply undercuts evidence from PAC density studies' routine assumption that the two interest populations are essentially isomorphic, they found that fewer than a fifth of all of the interest organizations both lobbied and made campaign 
contributions through a PAC. But when they turned their attention to contributions, a quite different pattern emerged. That is, fully 85.71 percent of all campaign contributions by PACs were made by the minority of both PACs and lobbying organizations that did both. PACs that were unaffiliated with a lobbying organization accounted for only 13.85 percent of all contributions. Based on effort as measured by size of contributions, the literature's claim that campaign contributions via PACs are best viewed as a lobbying tactic is strongly supported.

A study by Gray and Lowery (1997) focused on the states to develop and test another implication of the hypothesis that campaign contributions are about lobbying. They observed that if PAC contributions are about lobbying, they should be especially valuable in crowded interest systems where any communication with elected officials is more difficult. Importantly, this hypothesis cannot be readily tested at the national level given that the single population of PACs and lobby organizations at the national level. Indeed, such a hypothesis would even be difficult to test over time given that total numbers of PACs essentially stabilized in the mid-1980s (Lowery and Brasher 2004, 75). The 50 states provide, in contrast, considerable variation in both PAC numbers and lobby registrations. To test their conjecture, Gray and Lowery first examined survey data of interest group leaders, which indicated that those who perceived that they lobbied in a crowded, competitive environment were more likely to be affiliated with a PAC. Further, and especially important for our tests, they found using aggregate or total state PAC and lobbying numbers that that there was a strong positive relationship, but a convex one, as the relative size of the PAC population increases as the lobbying community becomes larger. ${ }^{4}$ Again, both of these results strongly support the expectation that PAC activity is ultimately about lobbying.

Still, while these studies have helped to clarify what was a somewhat muddy situation, several important questions remain. First and most simply, is the Tripathi et al. (2002) finding replicable beyond the single interest community found in Washington? Second, does the Gray

\footnotetext{
${ }^{4}$ This result stood in contrast to the Olsonian (1965) hypothesis that free-riding in larger interest systems would lead to a concave relationship where PAC reliance declined relatively in crowded communities.
} 
and Lowery (1997) finding of a convex relationship between numbers of registered lobby organizations and numbers of PACs apply to the levels of campaign contributions made by those PACs, the variable that was especially telling in the analysis of Tripathi and his colleagues? That is, do PAC contributions rise in a curvilinear manner as interest communities become more crowded? Third, if interest system crowding is related in the expected manner to both numbers of PACs and their campaign contributions, what kind of crowding matters? That is, interest organizations face both local and general competition for the time and attention of legislators with the former coming from those working in their immediate policy area and the latter from other organized interests with stakes in the policy process. Lowery and Gray (1997) only examined the relationship between the total lobbying and PAC populations. Focusing on the health interest system will allow us instead to examine crowding and competition within that subsystem and between it and all other organized interests. And fourth, what is the process by which crowding promotes greater reliance on PACs as a lobbying tactic? Does crowding lead to more affiliated PACs, to a growth of non-affiliated PACs, or both? And how does crowding influence the contribution patterns of the different types of PACs? We answer these questions by examining health lobby and campaign contributions in the 50 states.

\section{Answering the Questions}

\section{Data and Methods}

Two critical sources of data are used in our analysis. The first, which provides our dependent variables, is the data on contributions to state electoral campaigns provided by the National Institute on Money in State Politics. ${ }^{5}$ Several caveats about this data must be noted. First, while the National Institute refers to the organizations it lists as PACs, that name is not really appropriate in the sense in which is used in the data on national PACs. That is, not all states legally define PACs or, even when they do, define them in the same manner. Indeed, the

\footnotetext{
${ }^{5}$ National Institute on Money in State Politics. Political Giving Database. http://www.followthemoney.org /index.phtml (accessed 8/2007 - 9/2007).
} 
entities in the Institute's database include legally defined PACs, businesses, and other groups that probably are PACs (e.g. the Alabama Dental Association). Although, for simple convenience, we will continue to refer to these entities as PACs, they should more appropriately be interpreted as "non-individual, non-party" contributors to political campaigns. Second, the raw data generously provided by the Money and Politics Institute through special data requests still required considerable cleaning before they were usable. That is, the state lists included large numbers of individual contributors and duplication of contributors. Recoding to eliminate these cases reduced the initial list of 222,592 PACs to 162,352 PACs. Thus, our experience should serve as a cautionary tale to researchers who are using the Institute's data without further refinement. Third, we removed party leadership PACs from our data set on the grounds that theoretically they are not interest groups, the subject of our study. And fourth, 1998 data were not available for eight states usually due to their electoral calendars. In these cases, we used the most recently available data, which were from 1999 or $2000 .^{6}$ Nonetheless, we believe our data set is the best data on state health PACs in existence. And it matches up with our lobbying data set, which is critical to this study.

The second data set is an extension of the Gray and Lowery list of organizations registered to lobby in the 50 states in the late 1990 s. $^{7}$ In this analysis, we use 1998 lobby registrations given the available PAC data for 1998; thus we capture both forms of organized

\footnotetext{
${ }^{6}$ The exceptions are as follows: Arkansas (2000), Delaware (2000), Mississippi (1999), Nebraska (2000), New Jersey (1999), Oklahoma (2000), South Dakota (2000), Virginia (1999).

${ }^{7}$ The state lobby registration data we employ have been described more fully elsewhere (Gray and Lowery 2001). Briefly, however, lobby registration lists were gathered by mail or web page from state agencies responsible for their maintenance. After purging the lists of state agencies in states requiring their registration, organizations registered to lobby - rather than individual lobbyists - were coded by organizational type (membership group, institution, or association) and interest content ( 26 guilds of substantive interests) using directories of organizations and associations and the web pages of individual organizations. A second coder then examined the coding assignments with discrepancies resolved via discussion between the two coders. Only 1.58 percent of the 35,928 organizational lobby registrations in 1997 could not be coded by type or substantive interest. The organizations in the health category among the complete population of guilds were then recoded by substantive interest using the 18 categories reported in Lowery and Gray (2007). Only 38 organizations or 0.66 percent of the 1997 health population could not be coded by these categories of substantive interest. Fortunately, previous work indicates that the stringency of state lobbying registration requirements has little impact on the density (Lowery and Gray 1997; 1994) and diversity (Gray and Lowery 1998) of state interest communities.
} 
interest activity for a single year. Entities on both lists (whether PACs or lobby registrations) were individually identified as having health interests or not using the coding rules employed by Lowery and Gray (2007). The health PACs and lobby registrants were further coded by several subtypes of health interests using the same coding rules. ${ }^{8}$ Finally, the cleansed list of PACs was matched with the lobby registration data at the individual organization level to identify whether an organization was registered to lobby, contributed to political campaigns, or both. For the latter two categories, we also measured the size of the financial contribution the organization made to political campaigns for legislative, gubernatorial, all statewide offices, and judicial candidates.

We examine two dependent variables in the analyses to follow. The first is the number or density of the health PAC system in the state. The second is the total amount of contributions made by health PACs to political campaigns in the states. For both, we also conduct separate analyses for connected or affiliated health PACs (those with an affiliated organization registered to lobby) and unconnected or unaffiliated health PACs (those without an obvious affiliation with an organization registered to lobby the state legislature.

Three sets of independent variables are designed to test our core hypotheses that the PAC system is strongly connected to or a reflection of the lobbying system and that competition among lobbying organizations promotes PAC activity. Each focuses on a different locus of competition. The first and narrowest is the number of health lobby registrations. If PAC activity on the part of health interests is driven by competition among health interests, then there should be a strong positive relationship between the number of health PACs and their level of contributions and the number of lobby registrations. But these relationships should not be linear. That is, the marginal value of forming a health PAC as an additional channel of communication should increase as the number of health lobby registrations rise. Thus, the relationship should be convex with health

\footnotetext{
${ }^{8}$ The initial coding examined 18 subtypes of health organizations. Following Lowery and Gray (2007) we use a somewhat more aggregated set of health interests, including the following organizations: direct patient care, drugs and health products, health finance, local government health agencies, health care advocacy, health professional associations, and health education institutions
} 
PAC activity increasing at a faster rate as the number of health lobby registrations increase. To tap this convex relationship, the number of health lobby registrations is included as a second order polynomial where the nominal and squared values of the variable should define a positive, convex association. A second possibility, however, is that it is not competition within the health interest system that matters, but competition between health interests and all of the other types of organized interests seeking the attention of legislators. Thus the second independent variable is the number of non-health organizations registered to lobby in 1998. Again, this variable is included in a polynomial form to assess whether the relationship is convex as suggested by Gray and Lowery (1997). The third source of competition is from within the PAC system itself. That is, health PACs may have added value and/or may contribute more when the PAC system, not the lobby system per se, becomes more crowded. We measure such competition by the number of non-health PACs in a state, with the variable again included in a polynomial form to assess its convexity.

The OLS regression analyses also include three sets of control variables. The first set includes four variables broadly designed to account for structural differences in PAC activity across years and states. Most importantly, these include two dummies indicating via a value of one that no gubernatorial or general legislative election was held in the year in which PAC activity was measured. We also include a dummy indicating whether a legislature operated under term limits, which may increase (or decrease) opportunities for influence on the part of organized interests. And last, in terms of any cycles in PAC activity, we include a dummy identifying the eight states for which the PAC variables were measured in years after 1998.

The second set of controls includes two variables reflecting the energy term of Gray and Lowery’s (1996) Energy-Stability-Area model of interest system density. In numerous studies, they have found that lobby registrations rise with both the level of party competition in the states and the size of the political agenda associated with the concerns of a given sector of interests. We tap the former with the average of the folded Ranney Index of state party competition from 1997 
to 1999. ${ }^{9}$ Following Gray, Lowery, Fellowes, and Anderson (2005) we measure the size of the health policy agenda by the number of bills on health - as indicated by a "health" subject code considered by the legislature from 1997 to $1999 .{ }^{10}$ Importantly, the ESA model includes these variables in models examining variation in the number of lobby registrations in the states, another of our independent variables. It could well be the case that the impact of political and policy energy is expressed entirely through lobby registrations and, thus, that these controls will have no additional, independent impact on PAC activity. If so, this would be another, albeit indirect, indication of the dependence of the PAC system on the lobbying system.

The third and last set of controls is designed to account for differences in campaign finance laws in each state. ${ }^{11}$ Following Gray and Lowery (1997), we include dummy variables for states that prohibit direct contributions from corporations, labor unions, and regulated industries. We also include dummy variables for states that publish PAC contributions and for those states that cap PAC contributions. ${ }^{12}$

\footnotetext{
${ }^{9}$ Since this measure is inversely coded, with values near one indicating one-party dominance and values near 0.50 indicating balanced party strength, negative estimates will indicate that party competition promotes mobilization. Although the variation across years in the values of this variable is not great, we include the average to control for lagging and leading effects of political influences on PAC activity.

${ }^{10}$ Bill count data was collected from the "State Full Text of Bills" database on Nexis Academic Universe. The database is maintained by LexisNexis, a division of Reed Elsevier Inc, and is available for a fee at http://www.nexis.com. The database contains bill text files of all bills considered by each statehouse in a calendar year with each bill assigned a set of subject codes, providing a separate listing for each revised version of a bill in the database. For example, Alabama House Bill 175, which appropriated $\$ 4,564,831$ to the Department of Public Health in 1997, was listed five times in the database: one entry was the initial version, three were revisions, and the fifth was the enacted bill. Multiple counts are appropriate because the concerns of organized interests about bills should heighten as they move through the legislative process. Again, a although the variation across years in the values of this variable is not great, we include the average to control for lagging and leading effects of political influences on PAC activity. In terms of variation across states, the average number of bill counts in 1997 was 278 and ranged from a low of 17 in Kentucky to a high of 1,409 in California

${ }^{11}$ Campaign finance laws were gathered from: Edward D. Feigenbaum, and James A. Palmer. Campaign Finance Law 98: A Summary of State Campaign Finance Laws with Quick Reference Charts. Washington DC: Federal Election Commission, 1998. Term limit information gathered from: Jennie Drage Bowser “The Term Limited States.” February 2006. http://www.ncsl.org/programs/legismgt/about/states.htm (accessed 8/2007).

${ }^{12} \mathrm{We}$ also examined models in which these dummy variables were included only as interactions with the number of registered lobby organizations in the states. The results were essentially identical to those presented here. That is, they showed little evidence that these rules and regulations matter. We present the simple dummy results, however, because they introduced somewhat less collinearity into the analysis.
} 


\section{Findings}

We start by examining the relationship between registrations to lobby by organized interests and the PACs. Our expectation - based on Tripathi et al.'s analysis (2002) at the national level - is that affiliated PACs engage in the lion's-share of political activity thereby indicating that PAC activity is primarily a lobby tactic rather than an independent form of political engagement unconnected to traditional forms of lobbying. In terms of simple numbers of organizations, our results seem to be only somewhat similar to Tripathi et al.'s findings. As seen in figure 1 , only 13.98 percent of the 10,755 politically active health interest organizations have both a PAC and a lobby organization. Tripathi et al. found that $20 \%$ of national level organizations have both a lobbyist and a PAC $(2002,133)$. Thus, the conventional wisdom of a lobby group armed with its mighty PAC occurs only one fifth of the time at the national level and in our state-level health organizations only fourteen percent of the time. In contrast, figure 1 shows that unaffiliated or free-standing PACs account for 44.68 percent of such organizations, and organizations registered to lobby but lacking a PAC account for another 41.34 percent. Here our results depart from the national results. Tripathi et al. found that lobby only groups predominated, occurring 58 percent of the time. PAC only groups were only 22 percent of all organizations.

We can also look at the data a different way (data not shown): of all health PACs, 4,805 or 76.16 percent were not affiliated with a registered interest organization. Only 1,504 or 23.84 percent were so affiliated. If we look at the data in a still different way, of all organizations registered to lobby, only 1,504 or 25.28 percent had affiliated PACs. Fully 4,446 or 74.72 percent eschewed the opportunity to support a PAC as part of their lobbying activities. In terms of simple numbers then, these two forms of political activity - lobbying and PACS - seem largely unconnected.

This picture changes markedly, however, when we look at the actual political activity of state health PACs. That is, as seen in figure 2, it is the many fewer affiliated PACs that provide 
the lion's-share of funds to candidates. While connected or affiliated PACs accounted for only 23.84 percent of all PACs, they contributed over $\$ 34$ million or 75.69 percent of all contributions. In contrast, while unaffiliated PACs accounted for 76.16 percent of the PAC population, they made only $\$ 11$ million in contribution or 24.31 percent or all contributions. ${ }^{13}$ These aggregate numbers are reflected in the differences between mean contribution levels of non-connected and connected PACs. The mean contribution for non-connected PACs was only $\$ 2,319$ while the mean contribution for connected PACs was nearly ten times larger $(\$ 23,067) .{ }^{14}$ In terms of both total volume and average size then, the contribution activity of connected PACs dwarfs the activity of non-connected PACs. In terms of PAC activity, the state results parallel those at the national level where affiliated PACs contributed even more disproportionately, giving 86 percent of the total PAC contributions (Tripathi et al. 2002, 133). PAC activity is largely the province of organizations already engaged in lobbying. Given this connection, it seems reasonable to interpret such activity as a strategy designed to reinforce lobbying or as an adjunct to the lobbying activity.

In contrast to national-level studies, however, the multiple populations of the states allow us to explore the relationship between connected and non-connected PACs in ways not available to Tripathi and his colleagues. That is, there is significant variation across the states in the relative proportions of affiliated and unaffiliated PACs. Non-connected PACs account for only 11.11 percent of the PAC population in Montana and fully 92.02 percent in New York. One possibility suggested by these two extreme cases, of course, is that it is something about state size that accounts for this variation. This would certainly be plausible, for example, if the automobile

\footnotetext{
${ }^{13}$ This three to one ratio of contribution dollars from connected PACs to dollars from unconnected PACs is also true within contributions to each party. Connected PACs account for 74.05 percent of contributions to Democrats in the states and 76.78 percent of contributions to Republicans. Overall, GOP contributions $(\$ 25,368,300)$ somewhat exceed those to Democrats $(\$ 20,222,100)$. Note these numbers exclude a smaller amount of contributions to third party candidates. There are no significant differences in the two-party distribution of PAC contributions between non-connected and connected PACs.

${ }^{14}$ Due to the skewed nature of contributions, it is also useful to look at the differences in terms of median contributions. The median contribution for non-connected PACs is $\$ 500$, with an IQR of $\$ 200-1,000$. The median for connected PACs is $\$ 4,500$, with an IQR of $\$ 1,150-16,238$.
} 
dealership association in each state sponsored an affiliated PAC as part of its lobby effort while 10 percent of its member dealerships also sponsored an independent PAC. Because New York has so many more automobile dealerships than Montana, this would mean that the ratio of unconnected to total PACs would be much larger in the former. As plausible as this might seem, figure 3, which shows the relationship between proportion of non-connected PACs and gross state product, provides little support for it. That is, while the relationship is positive as we would expect, it is also exceptionally weak $\left(\mathrm{R}^{2}=0.03\right)$.

A potentially more fruitful line of inquiry, and one we pursue more fully when we turn to the PAC models, is suggested by figure 4, which presents the relationship between the proportion of unaffiliated or non-connected PACs and the total size of the PAC population in the states. The curvilinear line represents a simple polynomial relationship for all 50 states. As seen in the regression results, the proportion of unaffiliated PACs increases with the size of the total PAC population, if in a density dependent manner. This relationship accounts for 44 percent of the variation in the proportion of unaffiliated PACs. Clearly, however, this relationship is heavily influenced by the two outliers of New York and Florida on the right of the figure. However, when these two states are excluded, as seen in the truncated line on the left of the figure and the accompanying regression result, there remains a moderately strong $\left(\mathrm{R}^{2}=0.37\right)$ between the proportion of unaffiliated PACs and the total size of the PAC population. This relationship will become important as we now turn to testing the PAC density and contribution models.

Starting with the former, table 1 presents a series of OLS regression results (generated using robust standard errors based on states) where the dependent variables are numbers of PACs in states. Models 1 through 5 employ total PAC numbers - connected and non-connected - as dependent variables. The four sets of independent variables - grouped in shaded bars for ease of interpretation - represent our various measures of interest system crowding and the three sets of controls. We start by examining the control variables, which provide little evidence that they significantly influence PAC density. The first set of controls included potential political-temporal 
influences on PAC numbers, including the lack of gubernatorial and legislative elections, whether a state legislature was term-limited, and the dummy for the few states for which we were not able to employ 1998 PAC data. In all cases across all of the models, none of the estimates generated a t-value as large as the estimate. This suggests that PAC density is little influenced by electoral considerations, something that strikes against the notion that PACs are primarily about elections.

Similarly, the controls for political energy - the Ranney index and the size of the health policy agenda before a legislature - also generated quite weak results with only the Ranney estimate in model 3 producing a marginally significant estimate in the expected direction. The weakness of these results was somewhat surprising given that these variables have always generated very strong results when included in ESA models of the density of total and health lobby registrations in the states (Gray and Lowery 1996; Lowery, Gray, and Monogan 2008). Further reflection, however, suggests that this result might well be evidence of the lack of independence of the PAC system. The best interpretation, we believe, is that once lobby registrations were included in the model as our competition measures, discussed below, there is no additional value to political energy imparted to PAC formation and maintenance. Political energy in the form of the size of the health policy agenda and the level of political competition matter, but only in so far as they indirectly influence health PAC density through the size of health interest lobby community. Again, this suggests that PAC density is a derivative function of the forces determining the size of the population of organizations registered to lobby.

The final set of control variables include a series of dummy variables to account for variations in PAC regulations across the states. Surprisingly, these also generated very weak results. Only two sets of results are noteworthy. First, the dummy for prohibitions on corporate contributions came closest to matching our expectations in generating uniformly negative estimates, although in only models 4,6 , and 7 were these of sufficient magnitude to be considered discernibly different from zero at even relaxed criterion values. Still, it does seem that prohibiting corporate contributions might suppress PAC density. Second, in sharp contrast to our 
expectations, however, the dummy for no limits on PAC contributions produced uniformly negative estimates, several of which generated sizable t-values, albeit not in the expected direction. We had expected that caps on contribution limits would reduce the value of PAC influence for organized interests and, thus, the formation of health PACs. Instead, it seems that the opposite occurs. One strong possibility is that more PACs are formed in states with such limits so as to generate the same level of PAC contributions to candidates even if from a greater number of PACs. If so, than this type of control on PACs has proven largely ineffective.

We can now turn to the critical estimates for competition at the top of table 1. As noted earlier, we examine three sources of competition among organized interests that might lead to variation in the density of PACs: competition within the health lobbying community, competition within the lobbying system as a whole from other types of interests, and competition from other types of PACs. All three are included in model 1 in the form of polynomial specifications with both the nominal and squared value of the variable, thereby producing six interpretable estimates. Our expectations about these three pairs of estimates are two-fold. Most importantly, the squared term of the variables should always generate positive estimates indicating that greater competition among health lobby organizations (or all other lobby organization or all other PACs) is associated with high health PAC density. In contrast, the estimate for the nominal term of each pair might be positive or negative depending on the magnitude of the squared term. Together, however, each pair of estimates must define a convex relationship that is flat or rises slightly and then rises at an increasing rate as level of competition increases. Accordingly, we use two-tailed tests for estimates of the nominal component of each of the three variable pairs.

Unfortunately, there is considerable collinearity in these estimates, something that is hardly surprising given both the polynomial specification and the likely underlying relationships among the three sets of variables. Indeed, in model 1 , the $\mathrm{R}^{2}$-value generated by regressing the nominal value of health lobby registrations on the other independent variables was 0.99 while the comparable value for its squared term was 0.98 . Even in model 4 , which excludes other PAC 
numbers and other lobby registration numbers, the respective comparable values were 0.95 and 0.94. Thus, we employ somewhat relaxed criterion values and examine several additional models (models 2, 3, and 4) excluding combinations of the three pairs of competition variables. Still, the estimates strongly suggest that it is local lobbying competition - competition within the health lobbying community - that matters most. Across models 1 through 4 , the squared value of the number of health lobbying organizations is always positive and significant as expected. In contrast the estimate for its nominal value is negative in models 1 through 3 and either significant or closely approaching discernible values. In contrast, the estimates for the nominal and squared values of the number of other lobbying registrants and other PACs are quite mixed and considerably weaker. When we examined the reaction functions defined by nominal and squared pairs of other lobby organizations and other PACs, they had little net impact on the density of health PACs. ${ }^{15}$ Further, in additional models comparable to model 4, but substituting either the nominal and squared values for other lobbying registrants or other PACs for the nominal and squared values of health lobbying registrations, both respective pairs of estimates failed to generate discernible coefficients. ${ }^{16}$ Thus, while rather severe collinearity precludes us from definitively ruling out the possibility that more general forms of competition encourage the formation of health PACs, the pattern of results provides very little support for that interpretation. In contrast, we have consistent and strong evidence that competition among health lobby registrants is strongly related to the formation of health PACs.

The relationship is represented in the upper line in figure 5, which reflects the simplest version of the model as seen in model 5 in table 1 . This model includes only the nominal and squared terms of the health lobby registration variable and excludes both the measures of the

\footnotetext{
${ }^{15}$ In another analysis not presented in table 1, when model 4 was re-estimated including the nominal values of other lobby registrations and other PACs, neither generated a t-value greater than 1.0 while the estimate for the squared value of health lobbying registrations remained positive and highly significant.

${ }^{16}$ These result for these separate analyses are not presented in table 1. But in the other lobby registration model, the nominal term generated a $t$-value of 0.84 , while the $t$-value for the estimate of the squared term was 0.23 . In the other PAC model, the nominal term generated a t-value of 0.84 , while the $t$-value for the estimate of the squared term was 0.23 .
} 
other potential sources of competition and the three sets of controls. Still, model 5 produces estimates that are quite similar to those reported in models 1 through 4 and generates a sizable coefficient of determination of 0.54 . The response function in figure 5 is essentially flat across the low and moderate values of number of health lobby registrations and rises sharply as those numbers increase. In short, as competition among health lobby organizations increases with their density, the number of health PACs increases sharply. ${ }^{17}$

But does it influence all types of PACs in the same manner? Answers to this question are provided in models 6 and 7 in table 1, which replicate model 4 separately for connected and nonconnected PACs. As seen in model 6, there is no obvious competition effect for connected or affiliated PACs given the weakness of the squared term of the health lobby registration variable $(\mathrm{t}=0.83)$. As indicated by the positive and significant estimate for the nominal term of the variable, unconnected health PACs do increase in number as number of health lobby registrations increase. But the rate of PAC growth does not increase markedly as number of health lobby registrations grow. In contrast, as seen in model 7, there is strong evidence of such a competition effect among non-connected or unaffiliated PACs. This can be better seen in the two lower lines in figure 5, which report the reaction functions for connected and non-connected PACs using the simplest version of the model comparable to model 5 in table 1 . The reaction function for connected PACs is essentially linear while that for non-connected PACs rises sharply as number of health lobby registrations increase. Thus, competition among health lobby registrants is associated with an acceleration in the growth rate of non-connected health PACs.

This last result has two important implications. First, this difference in the reaction functions explains why we observed the positive relationship between the proportion of nonaffiliated PACs and total number of PACs in figure 4. As the health interest community becomes larger, we see an acceleration in the number of unaffiliated health PACs. Second, and more

\footnotetext{
${ }^{17}$ It is also worth noting that this relationship is the opposite of what we would expect if PAC formation was governed by an Olsonian collective action process. Thus, this result strongly supports the finding for general PAC activity presented by Lowery and Gray (1997).
} 
substantively, this result raises an important question about the true non-connectedness of unaffiliated PACs. If their numbers respond so strongly to the health lobby registrations, then there must be a connection. The most likely possibility is, we suspect, that they are in fact closely connected to the health interest system through a proliferation of smaller PACs representing not health associations per se but their members. That is, a trade association might well encourage its members to "independently" contribute to one or a few legislators representing either the districts in which the association member operates or to key positions in the legislature in which health policy issues are considered. In either case, the position of the health trade association, as represented through lobbying and the contributions of its affiliated PAC, would be amplified by the additional contributions from nominally independent PACs. Indeed, this interpretation would be consistent with the relatively few and small contributions typically made by non-connected PACs. By themselves, these would not likely have much impact. In combination with a broader strategy linking affiliated and non-affiliated PACs, they could well draw needed attention to the association's lobbying efforts in an increasingly crowded interest system.

We also assessed the robustness of our general finding by re-estimating model 4 in table 1 for six different subgroups of the health interest community representing interests associated with direct patient care organizations, local government health agencies, health professional associations, health finance organizations, health advocacy groups, and drug and health product firms and associations. The coding of these subgroups is described fully in Lowery, Gray, and Monogan (2008) where examples are provided for each. In general, the numbers of PACs representing these subgroups vary markedly in size. As seen in figure 6, direct patient PACs comprise almost two-thirds of the health PAC system, while only one percent represents health advocacy groups. Drugs and health products PACs comprise 15.2\%, and health professional PACs constitute $11.7 \%$ of the total, with local government and health finance PACs registering small percentages.

Basically, the more general result presented in table 1 is strongly replicated in table 2 for 
three of the subgroups - health finance, health professions, and patient care - and less strongly for health advocacy groups. ${ }^{18}$ Examination of the reaction function defined by the nominal and squared values of health lobby registrations for these four subtypes indicate a moderate curvilinear relationship for health advocacy groups and much stronger curvilinearity for the other three types of PACs. Together, these subtypes account for 83.06 percent of all health PACs. No evidence of a competition effect was observed for the drug and health product organizations or for local government health agencies. In general, while the specific reaction functions for the subtypes vary somewhat, ${ }^{19}$ the results reported in table 1 hold up quite well when the locus of analysis is taken to below the entire health interest community.

Finally, we can turn our attention to a second dependent variable - the financial contributions made by the health PAC community. That is, does the competition effect observed for numbers of health PACs also explain the level of health PAC contributions? The question is made interesting by the joint observations that the proportion of nominally unaffiliated PACs rises as interest systems become more crowded and unaffiliated PACs contribute much less on average than affiliated PACs. Some indication of this problem is evident in figure 7, which shows the relationship between average PAC contribution and number of lobby registrations. While the relationship is hardly strong $\left(\mathrm{R}^{2}=0.08\right)$, the relationship is negative. Is this decline in average contribution compensated for by having more PACs, especially unaffiliated PACs?

The answer seems to be yes. Table 3 replicates models 1 through 5 in table 1, but substitutes health PAC contributions for number of health PACs as the dependent variable. The pattern of estimates for the control variables is essentially identical to those reported for the models in table 1, and so we will say little about the control variables. More to the point, estimates for the three sets of competition variables also generated essentially the same results.

\footnotetext{
${ }^{18}$ We do not comment on the estimates for the three sets of controls in table 2 given that they are essentially the same as those reported for table 1.

${ }^{19}$ This variation in the reaction functions has implications for the changing diversity in substantive interests represented by the health PAC system as it grows in size, something that may well merit further analysis.
} 
Most importantly, the positive and significant estimates for the squared term of the health lobby registrations variable indicate that total health PAC contributions react to local competition - as measured by crowding of the health lobbying community - in a curvilinear pattern, rising sharply as the lobbying community grows. This relationship, as defined by model 5 in table 3 , is reported in figure 8 as the line sloping most strongly to the upper right. Again, contributions of all health PACs remain flat across the mid-range values of the density of lobby registrations by health organizations and then rise sharply. In short, even though most of the growth in the number of PACs at this upper range of lobbying density is via the addition of unaffiliated PACs, who tend to give less, there is still a marked increase in overall contributions.

Indeed, the last two columns in table 3 report separate analyses for connected and unconnected PACs and seem to indicate that levels of competition among lobby organizations influence the total contributions of both types of PACs. This is interesting given that we have seen both that connected PACs account for three-quarters of all contributions and that connected PAC numbers - unlike unaffiliated PACs - do not seem especially responsive to competition within the health interest community. While the estimate for the nominal term of registrations is somewhat weak in model 6 for connected PACs $(\mathrm{t}-0.36)$, the estimate of the squared term is strongly positive. The respective significant and oppositely signed estimates for health lobby registrations in model 8 for non-connected PACs also suggest a convex relationship. More telling, the separate estimates, when the response functions produced by the simplest form of the model including only the polynomial specification of lobby registrations are examined, as seen respectively - in the middle and lowest curves on the right hand side of figure 8 , it is clear that levels of contributions from both types of PACs increase with lobby density. Indeed, although we have seen their numbers do not rise with competition, contributions by connected health PACs grew more sharply in the face of greater competition than did the contributions of non-connected health PACs. Thus, the responsiveness of PAC contributions to competition among health interest organizations results, then, from two sources. Affiliated PACs seem to give more, and 
more unaffiliated PACs are created.

\section{Conclusion}

Several conclusions are warranted from this analysis. The first two concern our efforts to replicate two prior studies of the relationship between PACs and lobbying. First, our analysis provides strong support of Tripathi and his colleagues' (2002) findings on the relationship between national PAC activity and lobbying. As in their study, which was on all types of PACs, we found that the bulk of state health PAC contributions are provided by health organizations registered to lobby their state legislatures. Moreover, we found, as they did, that lobby groups with affiliated PACs are a rarity, constituting only about 14 percent of our set of health organizations.

And second, the empirical results also provide strong support for Gray and Lowery's (1997) finding that overall PAC numbers in the states are related in a positive, convex manner with overall lobbying activity as measured by lobby registrations. When their analysis was extended to the more specific level of health PACs, the same relationship was found for total health PACs and for many of the narrow sub-types of interests comprising the health interest community. In contrast to those who have argued either that the PAC system is largely disconnected from the larger lobbying system (Berry 1977, Wright 1985; Scholzman and Tierney 1986; Gais and Walker 1991) and/or that it can be studied with the same theoretical tools used to explain the density of the lobbying system (Andres 1985; Masters and Keim 1985; Boies 1989; Humphries 1991; McKeown 1994; Grier, Munger, and Roberts 1991; 1994; Conybeare and Squire 1994), we find that the PAC system is derivative of the larger interest system. It is lobby registrations - and little else - that drives PAC density and contributions. And lobby registrations are, in turn, largely driven by the availability of members to mobilize and the political and policy uncertainty that draw unorganized interests to political activity (Lowery, Gray, and Monogan 2008). Thus, the dynamics of the PAC system are a secondary effect of the process governing lobbying as described by Gray and Lowery's (1996) ESA model. 
Our analysis has done more, however, than simply replicate prior studies in a new context. We have examined much more closely how lobbying activity on the part of organized interests promotes PAC activity. Three new conclusions about that process are, we believe, evident in our findings. First, perhaps our most unexpected finding in this regard is that it is not the number of connected or affiliated PACs that increase in number as lobbying density increases, but the number of non-connected or unaffiliated PACs. The density of connected PACs has a simple linear relationship with lobby registrations, while the density of unaffiliated PACs rises ever more sharply as the number of lobby registrations increases. This suggests that the distinction between connected and non-connected PACs may be far less important than is usually thought. It also suggests that we should more closely examine the relationship between the two types of PACs. Second, we also found that lobby density increases contributions from both types of PACs. Crowding among organized interests puts a premium on giving more money whether or not a PAC is affiliated with a lobbying organization, although this effect seems especially strong among affiliated PACs, who, in any case, provide the bulk of contributions in the states. And third, we have found that it is local competition - competition within the health interest lobby system - that really matters. It was only for such local competition that the expected positive, but convex, relationship was found between lobby registrations and PAC activity. This broadly supports the conclusion that interest systems can be decomposed into subsystems in which actors stick to their knitting in terms of attending to their own concerns and not to those of the broader lobbying system (Heinz, Laumann, Nelson and Salisbury 1993).

Finally, what can our results tell us about the impact of PAC contributions on public policy in regard to health policy in the American states? In a strict sense, these findings tell us little in that we have not examined whether PAC activity - either in terms of numbers or level of contributions - influence decisions on health policy. However, if both PAC numbers and level of contributions are related in a systematic manner to numbers of lobby registrations as we have seen, then additional information on PACs tells us nothing really further than what we already 
know based on examinations of the relationship between health policy and health lobby registrations. The information on PACs is already embedded in the information on lobby registrations. And there, the answer from previous studies is quite mixed. It seems that the density and mix of lobby registrations by health interest organizations has influenced the adoption of managed care regulations in the states (Gray, Lowery, and Godwin 2007a), steps toward comprehensive health care (Gray, Lowery, Godwin, and Monogan 2005), and the implementation (but not the adoption) of pharmaceutical assistance programs (Gray, Lowery, and Godwin 2007b). Still, these effects are extremely varied and highly complex. It is far from the case that more activity on the part of organized interests always leads to policies favorable to those interests. Most importantly, all health organizations do not share a common set of interests on many policies. But if this is true, then the results that we have presented here also indicate that the influence of PAC contributions by health interests on health policy in the states is likely to be complex and varied, something far different from the caricature of powerful interests purchasing favorable policies in the face of public opposition. 
Table 1: Determinants of Number of Health PACs $(\mathbf{N}=\mathbf{5 0})$

\begin{tabular}{|c|c|c|c|c|c|c|c|}
\hline \multirow{3}{*}{$\begin{array}{l}\text { Independent } \\
\text { Variable }\end{array}$} & \multicolumn{7}{|c|}{ Dependent Variable } \\
\hline & \multicolumn{5}{|c|}{ No. of Health PACs } & \multirow{2}{*}{$\begin{array}{c}\text { Connected } \\
\text { Model } 6 \\
\end{array}$} & \multirow{2}{*}{$\begin{array}{c}\text { Unconnected } \\
\text { Model } 7 \\
\end{array}$} \\
\hline & Model 1 & Model 2 & Model 3 & Model 4 & Model 5 & & \\
\hline Health Lobby & $-4.72 \# \#$ & $-4.65 \# \# \#$ & $-2.89 \#$ & -2.32 & $-2.97 \# \#$ & 0.18 \#\# & $-2.48 \#$ \\
\hline Registrations & -2.48 & -2.09 & -1.54 & -1.40 & -1.87 & 1.86 & -1.54 \\
\hline Health Lobby & $0.02 * * *$ & $0.02 * * *$ & $0.01 * *$ & $0.01 * *$ & $0.02 * * *$ & 0.00 & $0.01 * *$ \\
\hline Registration Sq. & 3.36 & 3.31 & 1.78 & 2.18 & 2.50 & 0.87 & 2.20 \\
\hline Other Lobby & $0.55 \# \#$ & 0.38 & -- & -- & -- & -- & -- \\
\hline Registrations & 1.74 & 1.11 & & & & & \\
\hline Other Lobby & -0.01 & -0.01 & -- & -- & -- & -- & -- \\
\hline Registrations Sq. & -2.97 & -2.37 & & & & & \\
\hline No. of & 0.01 & -- & $0.04 \#$ & -- & -- & -- & -- \\
\hline Other PACs & 0.27 & & 1.59 & & & & \\
\hline No. of Other & 0.01 & -- & -0.01 & -- & -- & -- & -- \\
\hline PACs Sq. & 0.88 & & -0.63 & & & & \\
\hline No Governor & 36.72 & 44.19 & 11.19 & 12.49 & -- & -2.46 & 14.89 \\
\hline Election & 0.58 & 0.67 & 0.27 & 0.27 & & -0.49 & 0.34 \\
\hline No Legislative & -17.05 & -25.40 & 13.72 & -2.59 & -- & 2.14 & -4.86 \\
\hline Election & -0.52 & -0.56 & 0.40 & -0.07 & & 0.61 & -0.13 \\
\hline Term & -10.51 & 11.43 & -26.11 & -26.83 & -- & 3.21 & -30.12 \\
\hline Limited State & -0.27 & 0.26 & -0.49 & -0.53 & & 0.68 & -0.59 \\
\hline Non-1998 & -15.90 & -28.20 & 14.54 & 25.15 & -- & -1.49 & 26.61 \\
\hline Dummy & -0.30 & -0.47 & 0.28 & 0.45 & & -0.30 & 0.48 \\
\hline Size of Health & 0.08 & 0.17 & -0.19 & -12.00 & -- & 0.01 & -0.13 \\
\hline Agenda 1997-99 & 0.52 & 0.98 & -1.28 & -0.75 & & 0.57 & -0.79 \\
\hline Ranney Index & -234.08 & -155.25 & $-213.87 *$ & -79.89 & -- & 27.55 & -106.97 \\
\hline 1997-99 & -1.30 & -1.01 & -1.32 & -0.63 & & 2.06 & -0.82 \\
\hline Prohibit Corp. & -99.26 & -135.28 & -57.68 & $-157.82 *$ & -- & $-10.38 *$ & $-147.31 *$ \\
\hline Contributions & -1.05 & -1.13 & -0.65 & -1.40 & & -1.61 & -1.38 \\
\hline Prohibt Regulated & 105.08 & 86.22 & 83.95 & 83.53 & -- & -9.74 & 93.20 \\
\hline Contributions & 1.02 & 0.07 & 1.03 & 0.72 & & -1.22 & 0.85 \\
\hline Prohibit Labor & -26.72 & -30.65 & -26.06 & -17.62 & -- & 11.52 & -29.16 \\
\hline Contributions & -0.53 & -0.51 & -0.54 & -0.29 & & 1.85 & -0.52 \\
\hline Public & -26.75 & -47.51 & -11.67 & -49.21 & -- & -4.14 & -45.13 \\
\hline Financing & -0.75 & -0.91 & -0.33 & -0.99 & & -0.91 & -0.96 \\
\hline No. Contribution & -35.08 & -72.06 & -66.08 & -92.57 & -- & -1.39 & -90.92 \\
\hline Limit for PACs & -0.84 & -1.61 & -1.36 & -1.83 & & -0.30 & -1.87 \\
\hline State & -44.56 & -63.03 & -41.84 & -55.30 & -- & 4.81 & -60.03 \\
\hline Publication & -0.89 & -1.04 & -0.78 & -0.84 & & 0.99 & -0.94 \\
\hline Constant & 301.59 & 331.94 & 338.96 & 323.38 & 177.52 & -11.26 & 333.45 \\
\hline R-Square & 0.79 & 0.72 & 0.71 & 0.64 & 0.54 & 0.80 & 0.61 \\
\hline
\end{tabular}

$*=\mathrm{p}<0.10,{ }^{* *}=\mathrm{p}<0.05,{ }^{* * *}=\mathrm{p}<0.01$, one-tailed tests; values under the coefficients are $\mathrm{t}$-values generated with robust standard errors based on states; $\#=\mathrm{p}<0.15, \# \#=\mathrm{p}<0.10, \# \# \#=\mathrm{p}<0.05$, two-tailed tests. 
Table 2: Determinants of Sub-Guild Health PACs Contributions $(\mathbf{N}=50)$

\begin{tabular}{|c|c|c|c|c|c|c|}
\hline \multirow{3}{*}{$\begin{array}{l}\text { Independent } \\
\text { Variable } \\
\end{array}$} & \multicolumn{6}{|c|}{ Dependent Variable: No. of PACs } \\
\hline & Drugs \& & Health & Health & Health & Local & Patient \\
\hline & Products & Advocacy & Finance & Professions & Gov't & Care \\
\hline Health Lobby & 0.19 & -0.02 & -0.20 \#\# & -0.11 & 0.01 & $-2.19 \#$ \\
\hline Registrations & 1.36 & -1.31 & -1.90 & -1.30 & 0.39 & -1.58 \\
\hline Health Lobby & -0.01 & $0.01 * *$ & $0.01 * *$ & $0.01 * *$ & 0.01 & $0.01 * *$ \\
\hline Registration Sq. & -0.32 & 2.18 & 2.34 & 2.32 & 0.80 & 2.24 \\
\hline No Governor & 1.64 & 0.68 & 0.74 & 6.04 & 0.51 & 2.74 \\
\hline Election & 0.30 & 1.51 & 0.29 & 1.39 & 0.65 & 0.07 \\
\hline No Legislative & 0.47 & -0.11 & 1.46 & -0.73 & -0.48 & -3.39 \\
\hline Election & 0.06 & -0.23 & 0.65 & -0.24 & -0.67 & -0.11 \\
\hline Term & -2.97 & -0.39 & 0.95 & 0.41 & 0.15 & -24.74 \\
\hline Limited State & -0.39 & -0.70 & 0.39 & 0.15 & 0.15 & -0.59 \\
\hline Non-1998 & -2.30 & 0.05 & 0.64 & 0.13 & -0.16 & 26.62 \\
\hline Dummy & -0.22 & 0.08 & 0.21 & 0.04 & -0.67 & 0.55 \\
\hline Size of Health & 0.00 & -0.01 & -0.01 & $0.01 *$ & $0.00 * *$ & -0.13 \\
\hline Agenda 1997-99 & 0.08 & -0.07 & -1.00 & 1.60 & 1.87 & -0.93 \\
\hline Ranney Index & 2.03 & -0.69 & -6.45 & -5.66 & 3.36 & -72.39 \\
\hline $1997-99$ & 0.15 & -0.77 & -0.87 & -0.72 & 2.07 & -0.71 \\
\hline Prohibit Corp. & $-19.26 * *$ & 0.58 & -5.46 & -6.96 & -0.68 & -126.31 \\
\hline Contributions & -2.19 & 0.94 & -1.23 & -1.26 & -0.68 & -1.35 \\
\hline Prohibt Regulated & 3.00 & -0.52 & 1.35 & 5.06 & -0.68 & 75.53 \\
\hline Contributions & 0.30 & -0.81 & 0.30 & 0.83 & -0.62 & 0.78 \\
\hline Prohibit Labor & -0.76 & -0.13 & 1.10 & 2.32 & 0.45 & -20.5 \\
\hline Contributions & -0.09 & -0.20 & 0.40 & 0.59 & 0.32 & -0.43 \\
\hline Public & -8.48 & -0.66 & -0.44 & -0.73 & -1.19 & -37.56 \\
\hline Financing & -1.28 & -1.30 & -0.20 & -0.25 & -1.28 & -0.97 \\
\hline No Contribution & -3.26 & -0.70 & -5.66 & -3.72 & -1.57 & -77.63 \\
\hline Limit for PACs & -0.54 & -1.32 & -2.07 & -1.33 & -1.88 & -1.91 \\
\hline State & -7.40 & -0.38 & -2.40 & -1.41 & -0.29 & -43.36 \\
\hline Publication & -0.74 & -0.62 & -0.85 & -0.41 & -0.22 & -0.84 \\
\hline Constant & 12.47 & 2.04 & 20.13 & 15.52 & -0.97 & 273.88 \\
\hline R-Square & 0.48 & 0.61 & 0.70 & 0.75 & 0.52 & 0.63 \\
\hline
\end{tabular}

$*=\mathrm{p}<0.10, * *=\mathrm{p}<0.05, * * *=\mathrm{p}<0.01$, one-tailed tests; values under the coefficients are $\mathrm{t}$-values generated

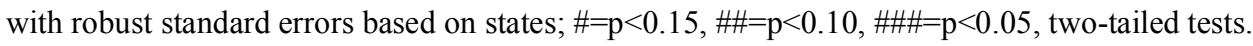


Table 3: Determinants of Health PACs Contributions $(\mathrm{N}=\mathbf{5 0})$

\begin{tabular}{|c|c|c|c|c|c|c|c|}
\hline \multirow{3}{*}{$\begin{array}{l}\text { Independent } \\
\text { Variable }\end{array}$} & \multicolumn{7}{|c|}{ Dependent Variable } \\
\hline & \multicolumn{5}{|c|}{ Health PAC Contributions } & \multirow{2}{*}{$\begin{array}{c}\text { Connected } \\
\text { Model } 6 \\
\end{array}$} & \multirow{2}{*}{$\begin{array}{c}\text { Unconnected } \\
\text { Model } 7 \\
\end{array}$} \\
\hline & Model 1 & Model 2 & Model 3 & Model 4 & Model 5 & & \\
\hline Health Lobby & $-0.41 \# \#$ & -42.09 \#\#\# & $-28.11 \# \#$ & $-23.59 \# \#$ & $-27.58 \# \#$ & -2.08 & $-2.72 \# \#$ \\
\hline Registrations & -2.36 & -2.22 & -1.74 & -1.64 & -1.85 & -0.36 & -1.30 \\
\hline Health Lobby & $0.19 * * *$ & $0.20 * * *$ & $0.12 * *$ & $0.12 * *$ & $0.12 * *$ & $0.03 *$ & $0.02 * *$ \\
\hline Registration Sq. & 2.94 & 3.05 & 1.92 & 2.10 & 2.09 & 1.62 & 2.33 \\
\hline Other Lobby & $4.13 \#$ & 3.08 & -- & -- & -- & -- & -- \\
\hline Registrations & 1.61 & 1.22 & & & & & \\
\hline Other Lobby & -0.01 & -0.01 & -- & -- & -- & -- & -- \\
\hline Registrations Sq. & -2.85 & -2.73 & & & & & \\
\hline No. of & -0.22 & -- & 0.25 & -- & -- & -- & -- \\
\hline Other PACs & -0.11 & & 1.16 & & & & \\
\hline No. of Other & 0.00 & -- & -0.01 & -- & -- & -- & -- \\
\hline PACs Sq. & 0.90 & & -0.63 & & & & \\
\hline No Governor & 202.48 & 242.71 & 10.03 & -7.64 & -- & 514.40 & -23.04 \\
\hline Election & 0.39 & 0.49 & 0.03 & -0.02 & & 1.31 & -0.27 \\
\hline No Legislative & -50.89 & -73.65 & 180.64 & 99.93 & -- & -236.27 & -83.66 \\
\hline Election & -0.17 & -0.20 & 0.55 & 0.30 & & -0.97 & -1.03 \\
\hline Term & 34.37 & 161.44 & -82.85 & -123.74 & -- & 103.62 & -59.21 \\
\hline Limited State & 0.10 & 0.45 & -0.20 & 0.33 & & 0.36 & -0.82 \\
\hline Non-1998 & -51.10 & -131.60 & 177.77 & 267.00 & -- & 34.43 & 149.96 \\
\hline Dummy & -0.11 & -0.27 & 0.38 & 0.56 & & 0.10 & 1.22 \\
\hline Size of Health & 0.25 & 0.63 & -1.79 & -1.55 & -- & $1.70 *$ & 0.21 \\
\hline Agenda 1997-99 & 0.18 & 0.50 & -1.42 & -1.15 & & 1.54 & 1.15 \\
\hline Ranney Index & -1674.73 & -1379.63 & -1523.07 & -823.51 & -- & 194.20 & -221.53 \\
\hline $1997-99$ & -1.09 & -1.00 & -1.10 & -0.72 & & 0.37 & -1.03 \\
\hline Prohibit Corp. & -780.83 & -854.86 & -467.87 & -1022.61 & -- & -114.79 & $-301.66 * *$ \\
\hline Contributions & -0.96 & -0.94 & -0.61 & -1.19 & & -0.38 & -1.71 \\
\hline Prohibt Regulated & 901.71 & 788.93 & 742.39 & 760.14 & -- & -166.87 & 207.75 \\
\hline Contributions & 1.02 & 0.80 & 1.02 & 0.86 & & -0.50 & 1.17 \\
\hline Prohibit Labor & -193.02 & -227.14 & -188.14 & -129.31 & -- & -65.15 & -52.43 \\
\hline Contributions & -0.43 & -0.48 & -0.44 & -0.28 & & -0.26 & -0.53 \\
\hline Public & -143.52 & -215.53 & -29.76 & -220.86 & -- & -115.35 & -15.39 \\
\hline Financing & -0.48 & -0.56 & -0.10 & -0.62 & & -0.45 & -0.16 \\
\hline No Contribution & -379.85 & -570.13 & -612.97 & -718.33 & -- & 98.55 & -145.07 \\
\hline Limit for PACs & -1.03 & -1.63 & -1.41 & -1.82 & & 0.46 & -1.82 \\
\hline State & -329.94 & -420.70 & -309.51 & -362.98 & -- & -181.36 & -124.56 \\
\hline Publication & -0.78 & -0.95 & -0.71 & -0.78 & & -0.75 & -1.28 \\
\hline Constant & 2503.75 & 2705.77 & 2785.69 & 2661.71 & 1543.96 & 0.27 & 459.79 \\
\hline R-Square & 0.71 & 0.67 & 0.62 & 0.74 & 0.49 & 0.72 & 0.69 \\
\hline
\end{tabular}

$*=\mathrm{p}<0.10, * *=\mathrm{p}<0.05, * * *=\mathrm{p}<0.01$, one-tailed tests; values under the coefficients are t-values generated with robust

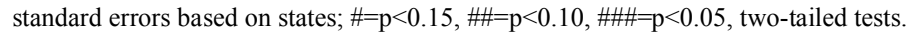


Figure 1: Distribution of Types of Connected and Unconnected PACs

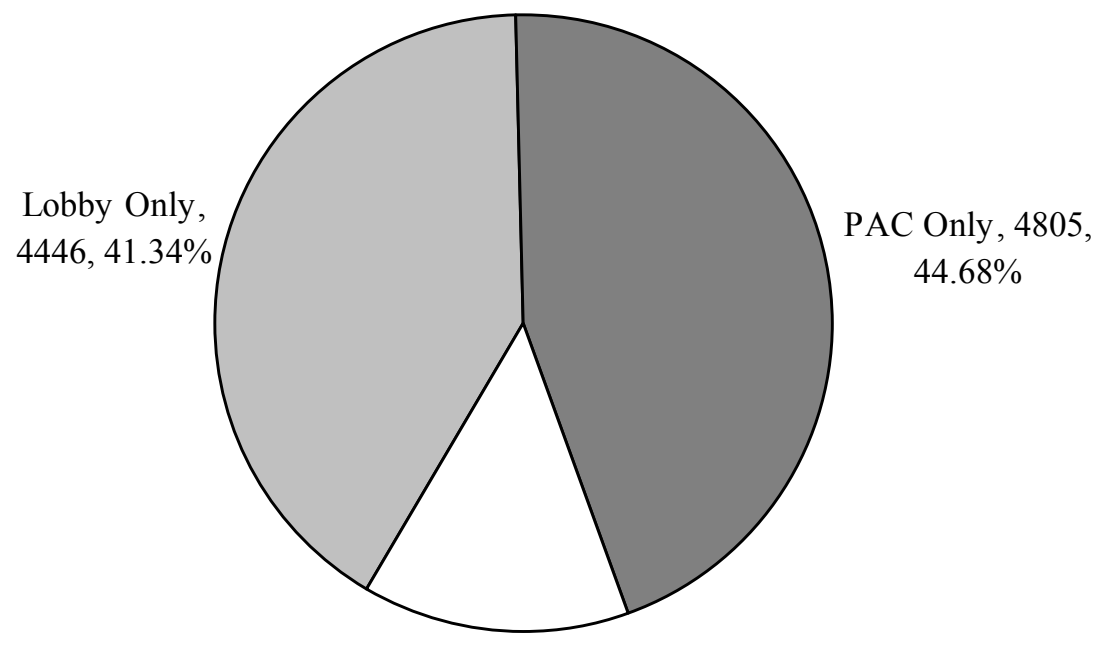

Both, 1504,

$13.98 \%$

Figure 2: Contributions by Connected and Unconnected PACs

PAC,

$\$ 11,141,270.00$ $24.31 \%$

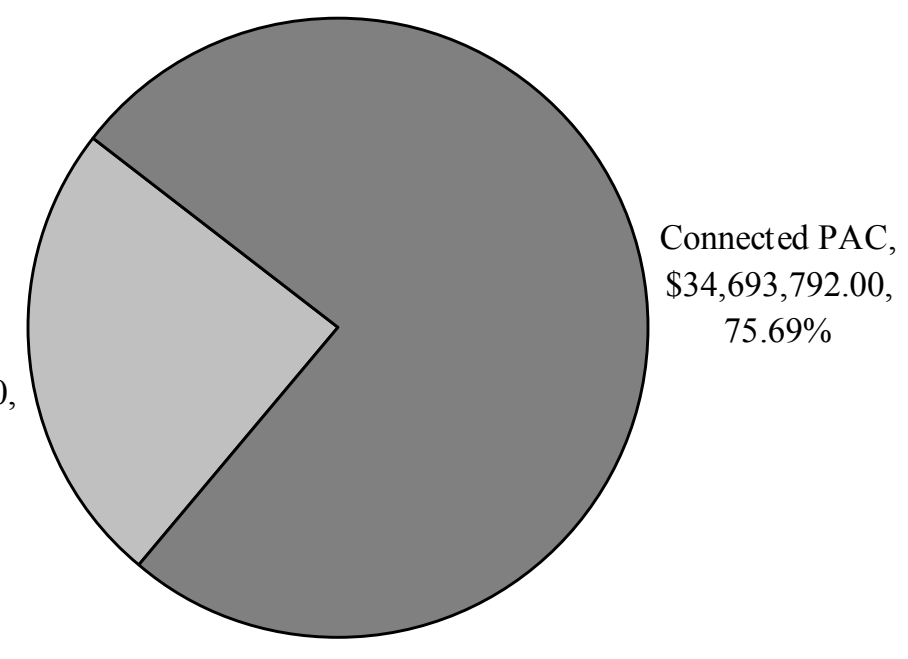


Figure 3: Relation of Proportion of Nonconnected PACs and GSP, 1998

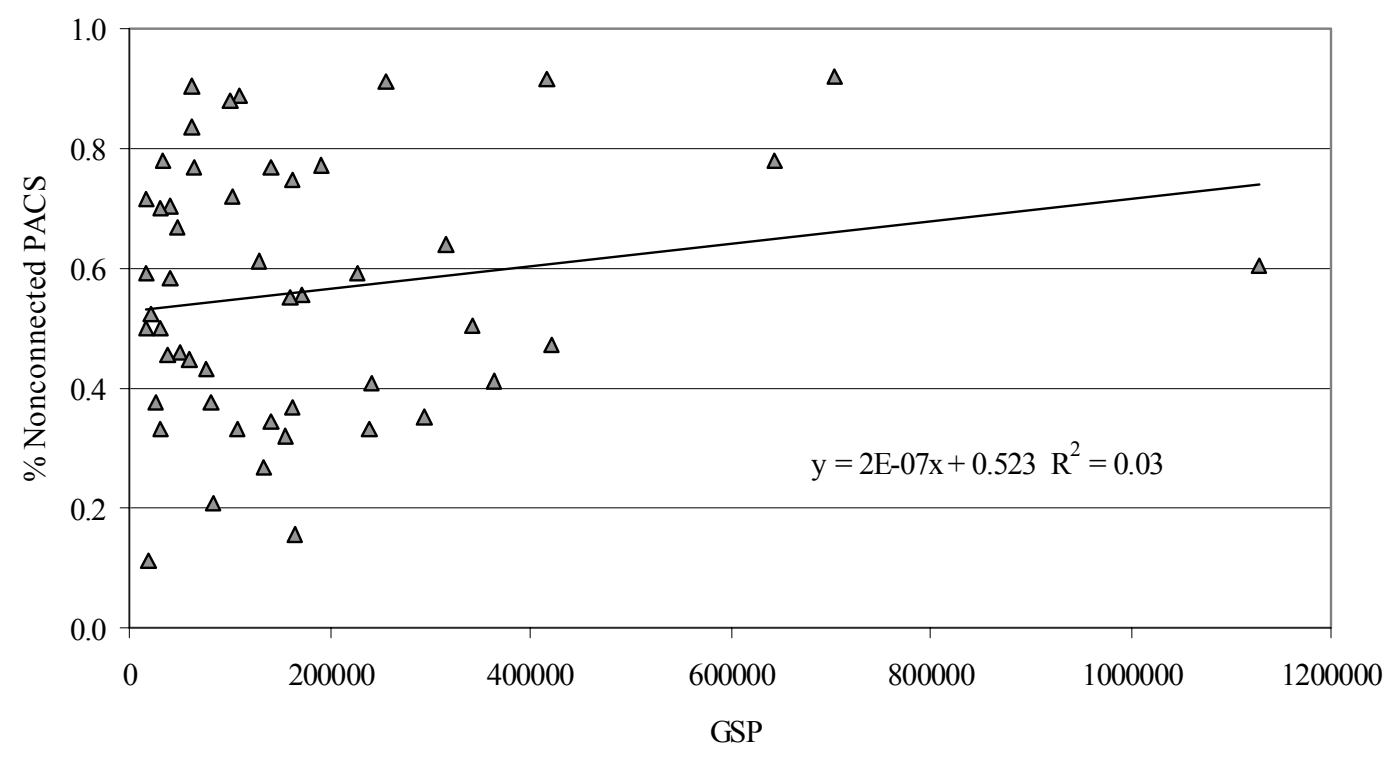

Figure 4: Relation of Proportion of Nonconnected

PACs and No. of Health PACs, 1998

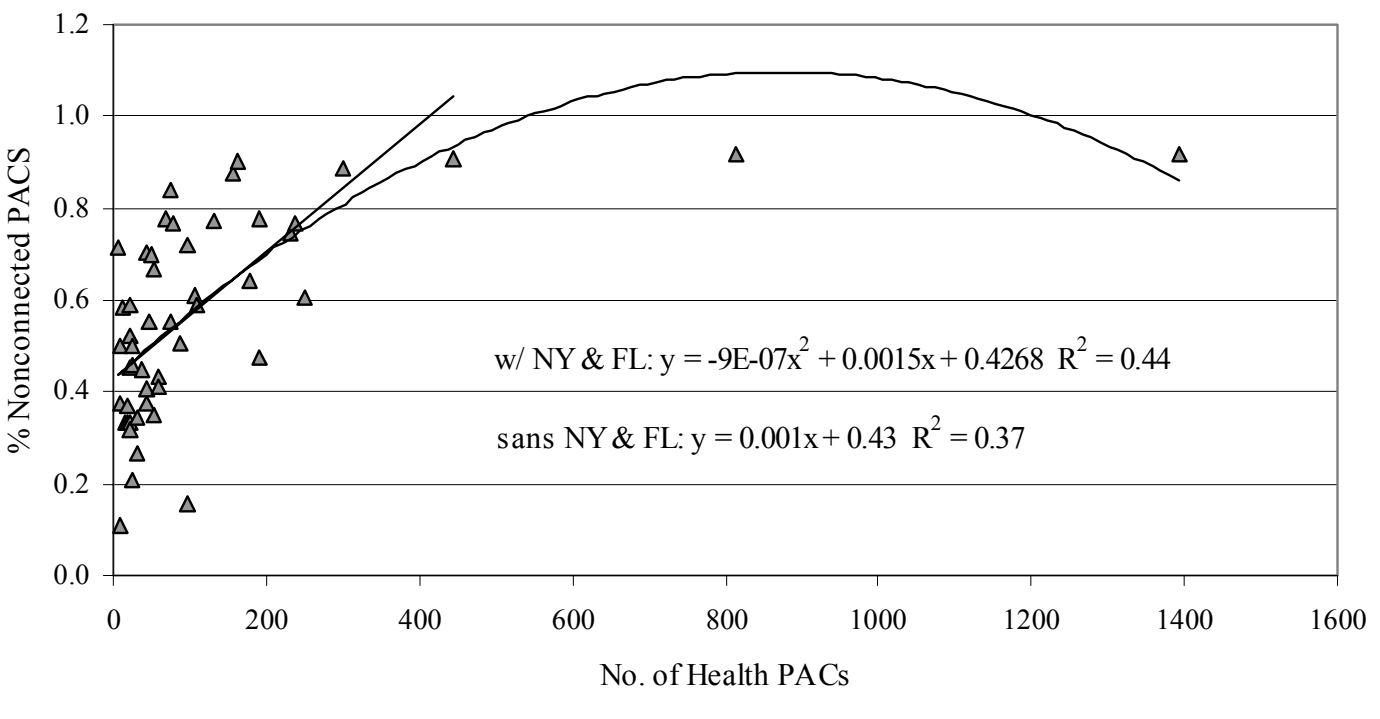




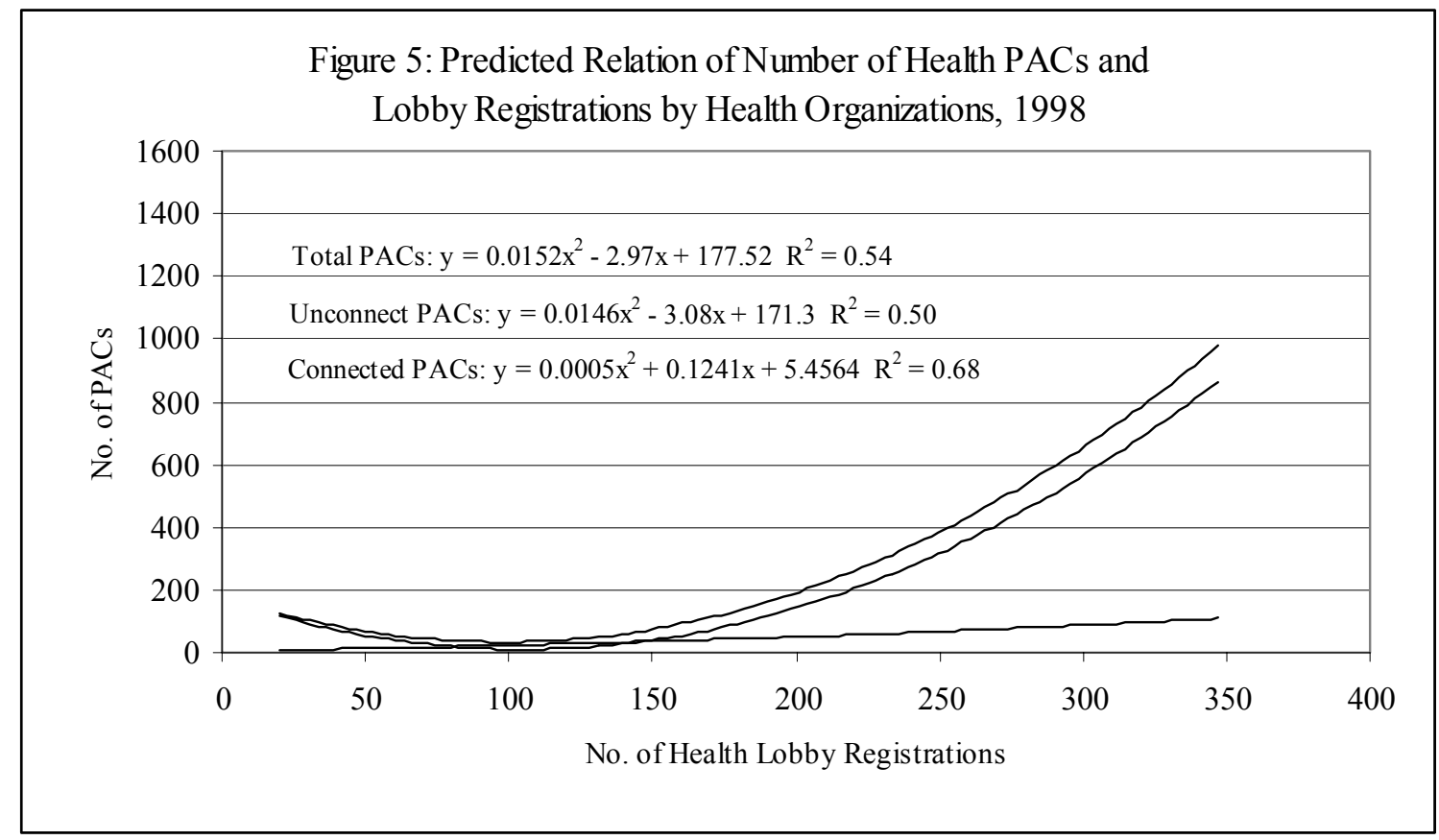

Figure 6: Dis tribution of PACs by Health Subguilds

Local Gov't, 102,

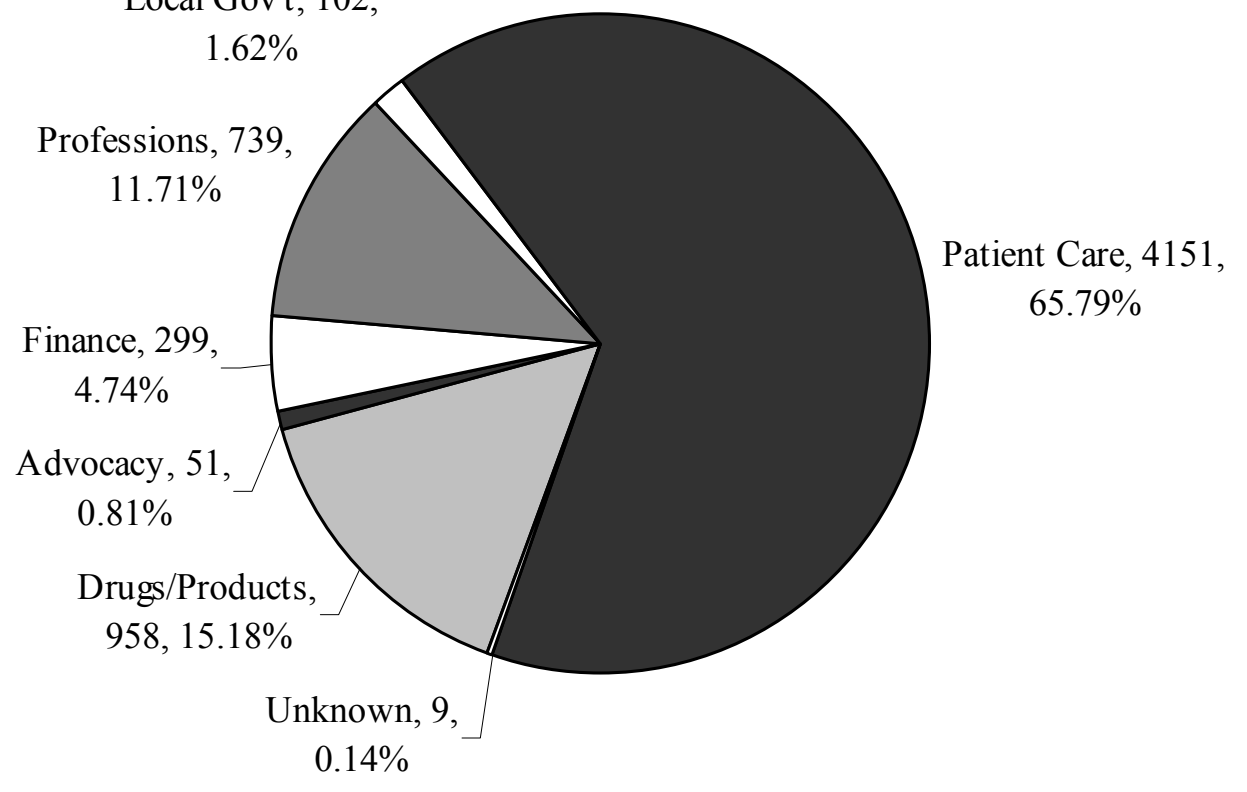



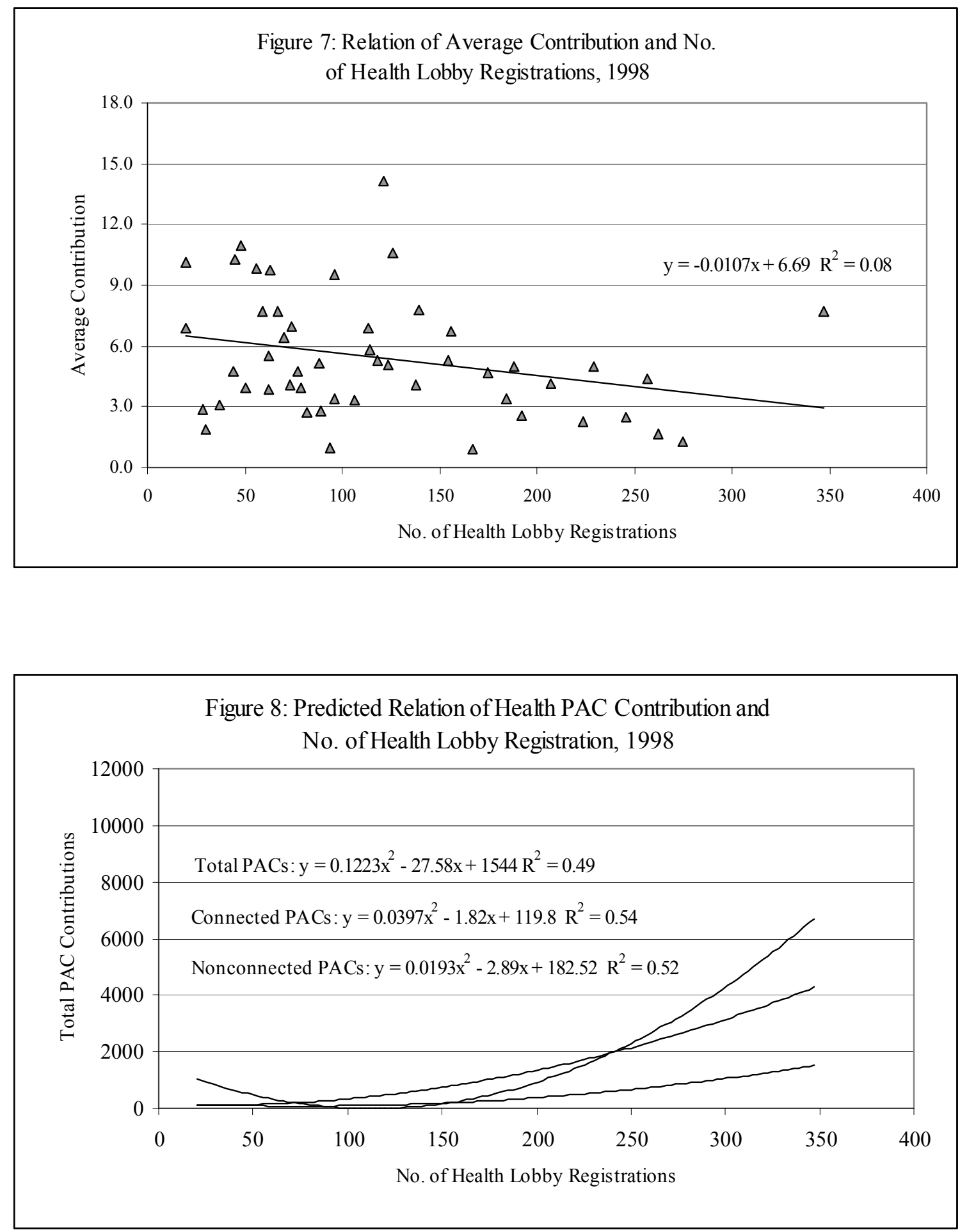


\section{References}

Andres, Gary J. 1985. Business involvement in campaign finance: Factors influencing the decision to form a corporate PAC. PS 18, (2) (Spring): 213-20.

Berry, Jeffrey. 1977. Lobbying for the people: The political behavior of public interest groups. Princeton: Princeton University Press.

Boies, John L. 1989. Money, business, and the state: Material interests, fortune 500 corporations, and the size of political action committees. American Sociological Review 54, (5) (Oct.): 821-33.

Conybeare, John A.C., Peverill Squire. 1994. Political action committees and the tragedy of the commons: The case of nonconnected PACs. American Politics Research 22, (2): 154-74.

Gais, Thomas and Jack Walker Jr. 1991. Pathways to influence in American politics. In mobilizing interest groups in America, edited by Jack Walker Jr. Ann Arbor: University of Michigan Press.

Gray, Virginia, and David Lowery. 2001. The institutionalization of state communities of organized interests. Political Research Quarterly 54, (2) (Jun.): 265-84.

1998. The density of state interest-communities: Do regional variables matter? Publius 28, (2) (Spring): 61-79.

1997. Reconceptualizing PAC formation: It's not a collective action problem, and it may be an arms race. American Politics Quarterly 25, (3): 319-46.

1996. The population ecology of interest representation: Lobbying communities in the American states. Ann Arbor, Michigan: University of Michigan Press.

1994. Do lobbying regulations influence lobbying registrations? Social Science Quarterly 75, (2): 382-84.

Gray, Virginia, David Lowery, Matthew Fellowes, and Jennifer L. Anderson. 2005. Legislative agendas and interest advocacy: Understanding the demand side of lobbying. American Politics Research 33, (3): 404-34.

Gray, Virginia, David Lowery, and Erik Godwin. 2007a. The political management of managed care: Explaining variation in state HMO regulations. Journal of Health Politics, Policy, and Law 32, (3) (Jun.): 457- 95. 
2007b. Public preferences and organized interests in health policy: State pharmacy assistance programs as innovations. Journal of Health Politics, Policy, and Law 32, (1) (Feb.): 89-129.

Gray, Virginia, David Lowery, Erik Godwin, and James Monogan. 2005. Incrementing toward nowhere: Universal health care coverage in the states. Under review. Presented at the Annual Meeting of the American Political Science Association, September, Washington.

Grenzke, Janet M. 1989. PACs and the congressional supermarket: The currency is complex. American Journal of Political Science 33, (1) (Feb.): 1-24.

Grier, Kevin B., Michael C. Munger, and Brian E. Roberts. 1994. The determinants of industry political activity, 1978-1986. The American Political Science Review 88, (4) (Dec.): 911-26.

- 1991. The industrial organization of corporate political participation. Southern Economic Journal 57, (3) (Jan.): 727-38.

Hall, Richard L., and Frank W. Wayman. 1990. Buying time: Moneyed interests and the mobilization of bias in congressional committees. The American Political Science Review 84, (3) (Sep.): 797-820.

Heinz, John, Edward Laumann, Robert Nelson, and Robert Salisbury. 1993. The hollow core: Private interests in national policy making. Cambridge, Mass.: Harvard University Press.

Herndon, James F. 1982. Access, record, and competition as influences on interest group contributions to congressional campaigns. The Journal of Politics 44, (4) (Nov.): 996-1019.

Humphries, Craig. 1991. Corporations, PACs and the strategic link between contributions and lobbying activities. The Western Political Quarterly 44, (2) (Jun.): 353-72.

Jamieson, Kathleen H. 1994a. The role of advertising in the health care reform debate: Part One. Press release issued by the Annenberg Public Policy Center of the University of Pennsylvania, July 18.

- 1994b. The role of advertising in the health care reform debate: Part One. Press release issued by the Annenberg Public Policy Center of the University of Pennsylvania, July 25.

1994c. The role of advertising in the health care reform debate: Part One. Press release issued by the Annenberg Public Policy Center of the University of Pennsylvania, Aug 1.

Johnson H., and D.S. Broder. 1996. The system: The American way of politics at the breaking point. Boston: Little, Brown. 
Lowery, David, and Holly Brasher. 2004. Organized interests and American government. Boston: McGraw Hill.

Lowery, David and Virginia Gray. 2007. Understanding interest system diversity: Health interest communities in the American states. Business and Politics 9, (2) (Aug.): Article 2.

Lowery, David, Virginia Gray, and James Monogan. Forthcoming 2008. The construction of interest communities: Distinguishing bottom-up and top-down models. The Journal of Politics.

Masters, Marick F., and Gerald D. Keim. 1985. Determinants of PAC participation among large corporations. The Journal of Politics 47, (4) (Nov.): 1158-73.

Matasar, Ann B. 1986. Corporate PACs and federal campaign financing laws: Use or abuse of power? Westport, Conn.: Quorum Books.

McKeown, Timothy J. 1994. The epidemiology of corporate PAC formation, 1975-84. Journal of Economic Behavior and Organization 24, (2) (Jul.): 153-68.

Nownes, Anthony J., and Patricia Freeman. 1998. Interest group activity in the states. The Journal of Politics 60, (1) (Feb.): 86-112.

Olson, Mancur. 1965. The logic of collective action; public goods and the theory of groups. Harvard economic studies. Vol. 124. Cambridge, Mass.: Harvard University Press.

Quadagno, Jill S. 2005. One nation, uninsured: Why the U.S. has no national health insurance. Oxford; New York: Oxford University Press.

Sabato, Larry. 1984. PAC power: Inside the world of political action committees. 1st ed. New York: Norton.

Schlozman, Kay and John Tierney. 1986. Organized interests in American democracy. New York: Harper Collins Press.

Sorauf, Frank J. 1984. Who's in charge? Accountability in political action committees. Political Science Quarterly 99, (4) (Winter): 591-614.

Tripathi, Micky, Stephen Ansolabehere, and James M. Snyder Jr. 2002. Are PAC contributions and lobbying linked? New evidence from the 1995 Lobby Disclosure Act. Business and Politics 4, (2): 131-55.

Weissert, Carol S., and William G. Weissert. 2002. Governing health: The politics of health policy. 2nd ed. Baltimore, Md.: Johns Hopkins University Press. 
West, Darrell M., Diane Heith, and Chris Goodwin. 1996. Harry and Louise go to Washington: Political advertising and health care reform. Journal of Health Politics Policy and Law 21, (1) (Spring): 35-68.

West, Darrell M., and Burdett A. Loomis. 1998. The sound of money: How political interests get what they want. New York: W.W. Norton.

Wright, John R. 1990. Contributions, lobbying, and committee voting in the U.S. house of representatives. The American Political Science Review 84, (2) (Jun.): 417-38.

1989. PAC contributions, lobbying, and representation. The Journal of Politics 51, (3) (Aug.): 713-29.

1985. PACs, contributions, and roll calls: An organizational perspective. The American Political Science Review 79, (2) (Jun.): 400-14. 